\title{
Education for Advancing the Implementation of the Green Deal Goals for Bioeconomy
}

\author{
Antra KALNBALKITE ${ }^{1 *}$, Jelena PUBULE ${ }^{2}$, Dagnija BLUMBERGA ${ }^{3}$ \\ ${ }^{1-3}$ Riga Technical University, Faculty of Electrical and Environmental Engineering, Institute of Energy \\ Systems and Environment, Azenes street 12/K1, LV-1048, Riga, Latvia
}

\begin{abstract}
Evolving complex concepts, such as bioeconomy, in the most effective way, can be applied through the education of students and professionals. In recent years changes in the education system can be observed with the development of knowledge-based learning. Competence-based learning will also be used more and more in higher education. Higher education plays a crucial role in achieving the goals of the Green Deal and the bioeconomy. The main emphasis is on creating new and innovative technologies and methods to achieve these goals. A new master's study program, 'Environmental Engineering', has been established at the Institute of Energy Systems and Environment of Riga Technical University. One of the study directions is 'Bioeconomy'. Considering the developed direction 'Bioeconomy', the importance of this sector is visible. Attention should also be paid to the goals of the Green Deal. This study summarised research on education, bioeconomy and Green Deal topics and analysed the interrelationships between these studies using the VOSviewer tool. During the analysis, it is possible to conclude the main keywords that characterise these studies. The obtained keywords should indicate the development trends of future research, which is in line with education, the 'Green Deal', and bioeconomy.
\end{abstract}

Keywords - Competency-based education; higher education; sustainable education; VOSviewer

\section{INTRODUCTION}

In global developments, it is crucial to consider development trends and the necessary solutions to achieve the goals. In 2012, the European Commission set five critical goals under the Bioeconomy Strategy:

1. Ensuring access to food and nutrition;

2. Sustainable management of natural resources;

3. Reducing dependence on non-renewable, unsustainable resources;

4. Limiting and adapting to climate change;

5. Strengthen European competitiveness and create jobs to foster the development of the bioeconomy [1].

Also, in the Latvian context, the 'Bioeconomy Strategy' was introduced in 2016, which defines several pillars based on knowledge and innovation, one of which is the provision of excellent educational services for the needs of the bioeconomy sector [2].

In 2020, the Institute of Energy Systems and Environment of Riga Technical University accredited the master's study program 'Environmental Engineering' with the direction 'Bioeconomy'. The establishment of this direction justifies the even greater need and

\footnotetext{
${ }^{*}$ Corresponding author.

E-mail address: antra.kalnbalkite@rtu.lv 
importance for bioeconomy specialists and their role in the future and in achieving the goals of the bioeconomy. Therefore, in the context of changes in education, the competencies (knowledge) acquired by students play an essential role [3].

At the end of 2019, the European Commission issued an action plan, 'Green Deal', which defines the action directions to accelerate the intensity of innovation and activate education [4].

The number of research in bioeconomy education has been growing over the past years to stress the necessity for new specialists in the field to devlope innovative technologies and products [5]-[11]. [12] writes that implementing bioeconomy goals and transforming to a knowledge-based sustainable bioeconomy should be considered transdisciplinary, learning, interdisciplinary and system-thinking, anticipatory, normative, strategic and interpersonal competence, where [13] ads policy and decision-making skills. Another paper [12] mentions that lectures, site visits, group coursework, practical laboratory work, and role-play support those competencies. Fig. 1 illustrates solving problems - a basic structure linked to key competencies for sustainability, which is described in [7].

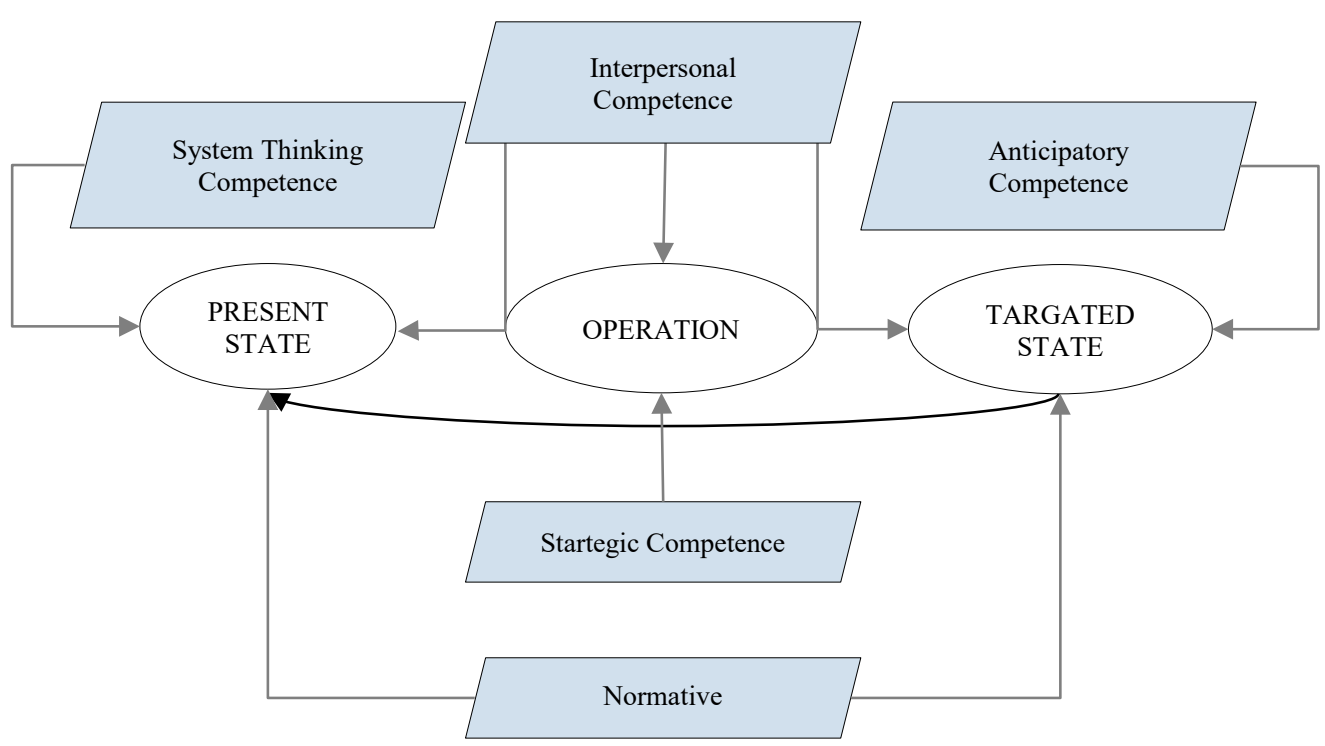

Fig. 1. Solving problems — basic structure linked to key competencies for sustainability [14].

In the [15], it is mentioned that skills are the solution to the bioeconomy and Green Deal goal-reaching victory. The agenda says a 'twin transition' supporting the green transition and digital transition skills in how the European Commission will support those skills. This agenda sets out the conditions under which the European Commission will support skills for the green transition, such as defining a system of skills and agreeing with the EU Member States on sets of indicators to monitor and analyse the development of green skills.

This study gathers information on research related to the bioeconomy, Green Deal, and education. The study's primary goal is to identify the most used keywords deciphered in the studies so far, using the bibliographic software VOSviewer to identify research trends. 


\section{Methodology}

The research methodology consists of

- Selection of articles from the Scopus database;

- Processing of articles using the bibliography visualisation program VOSviewer;

- Analysis of results;

- Conclusions (see Fig. 2).

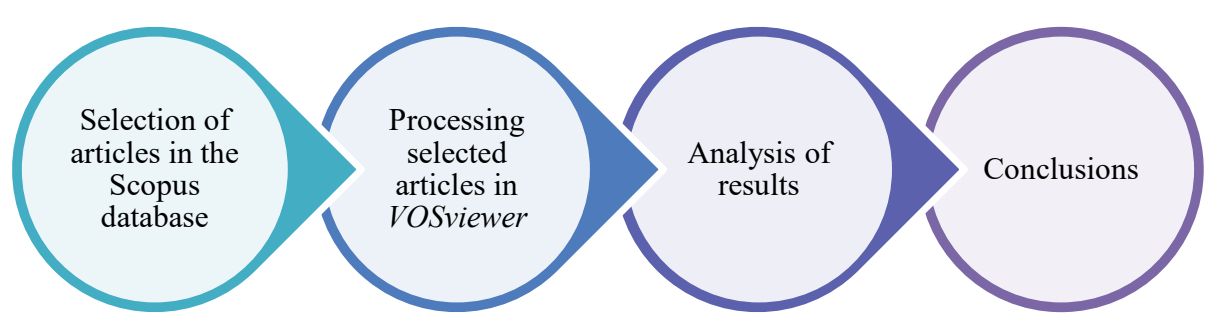

Fig. 2. Research methodology.

Articles were selected using the Scopus database and entering 'Article title, Abstract, Keywords' word combinations in the search fields. These word combinations are:

- 'Education' AND 'Bioeconomy';

- 'Education' AND 'Bioeconomy’ AND 'Competences';

- 'Education’ AND ‘Bioeconomy’ AND ‘Innovation’;

- 'Education' AND 'Bioeconomy' AND 'Skill’;

- 'Education' AND 'Green deal';

- 'Education' AND 'Green deal' AND 'Innovation'.

Articles were selected in the period starting from 2012 if the word 'bioeconomy' was included because in 2012 bioeconomy goals were set. If the word combination contained 'green deal', then the articles were selected starting from 2019 because the goals of the Green Deal came into force starting from 2019.

\section{REsults}

This study focuses on the research in the scientific literature related to education and bioeconomy, the link between education and the Green Deal, and the addition of additional keywords that are specific to the field of study. VOSViewer software is a good visualisation tool for bibliographic sources created by Nees Jan van Eck and Ludo Waltman [16], which gives the reader a general idea of the directions and connections of the research topic. In previous studies on sustainable development, circular economics and other environmental policy issues, VOSviewer has been used to identify critical keywords, key researchers and scientists in developing research directions, and research in the specific region and journals [17], [18]. 
Fig. 3 and Fig. 4 show the link between scientific articles using the words 'education' and 'bioeconomy' (articles were selected from 2012 onwards). Sixty-five articles were established in the Scopus database. These figures show significant differences in the minimum frequency of word repetition. In Fig. 3, this minimum frequency of word repetition is twice, but in Fig. 4 - three times. The minimum frequency of word repetition was changed because the authors considered that the connection of words should be visualised, and more relevant related words should be visualised. As shown in the figures (Fig. 3 and Fig. 4), the relationship of these words forms clusters. Fig. 3 shows 101 keywords that form eight clusters. Clusters consist of corresponding keywords and their links.

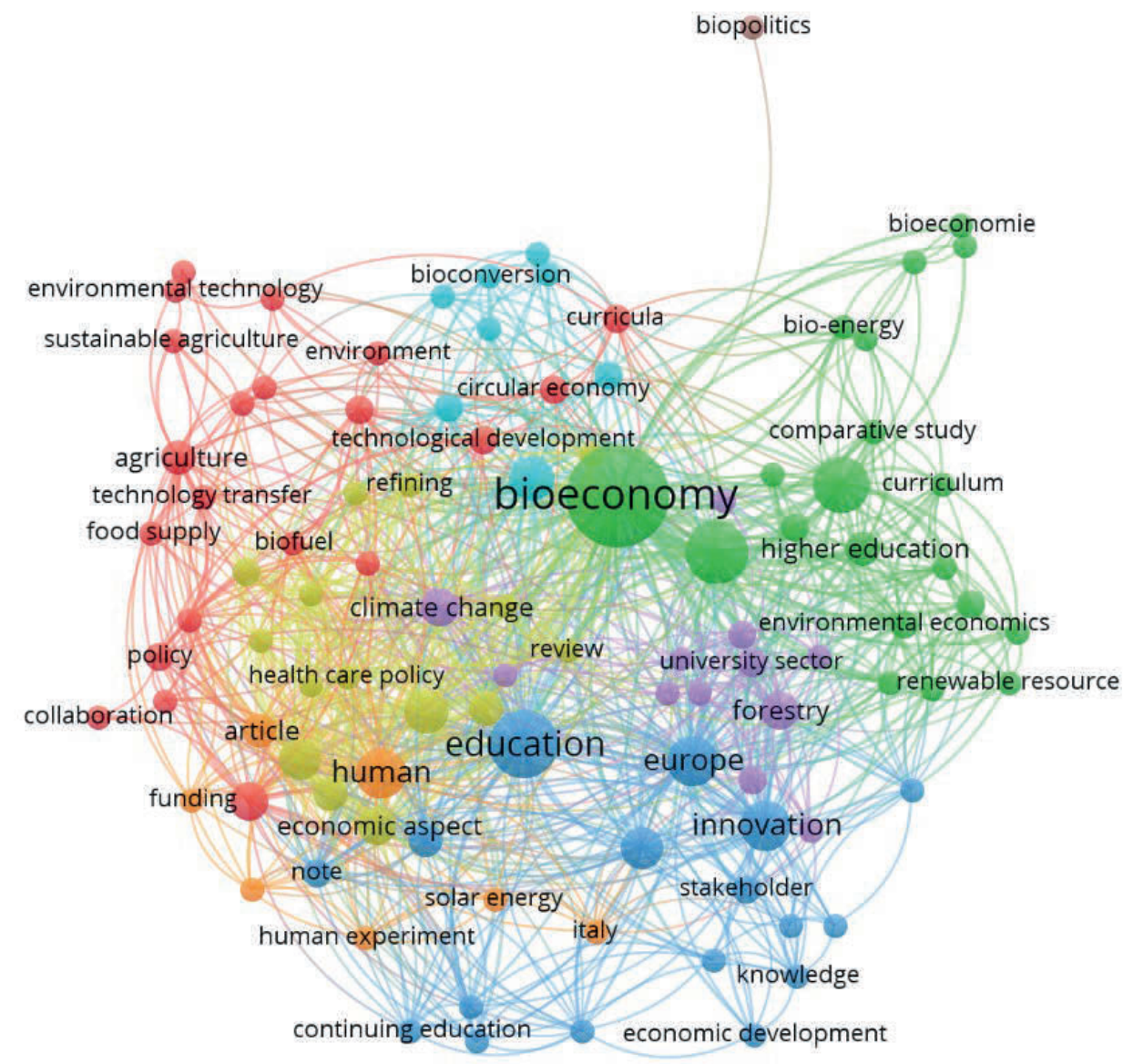

Fig. 3. Visualisation of the bibliography with the word combination 'education' AND 'bioeconomy' since 2012 (minimum frequency of word repetition -2 times).

Fig. 4 represents 37 keywords, which are classified into 4 clusters. Further, bibliographic data with the word combination 'education' and 'bioeconomy' since 2012 (minimum frequency of word repetition -3 times) is analysed, keywords identified by 4 clusters. 


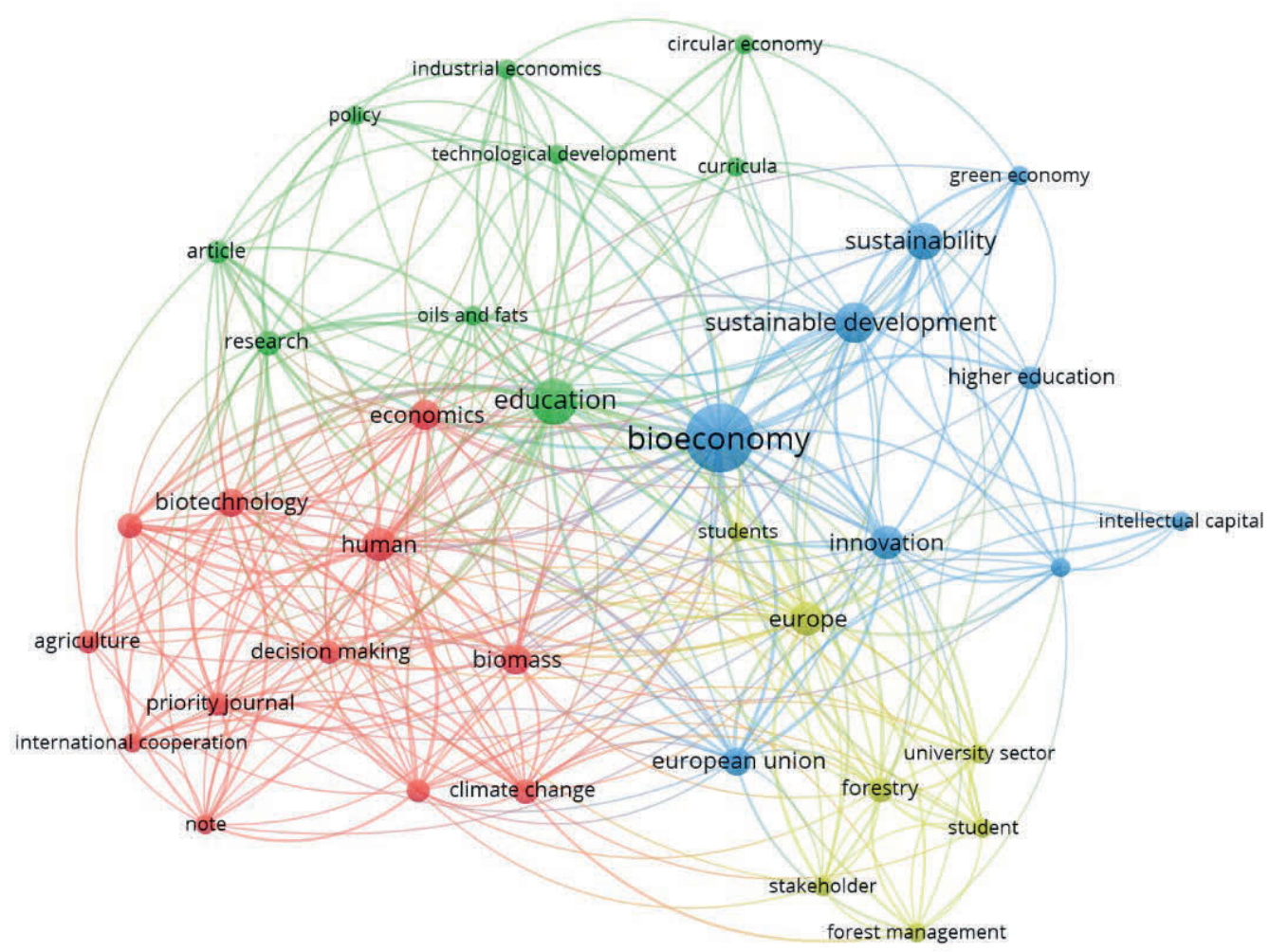

Fig. 4. Visualisation of the bibliography with the word combination 'education' and 'bioeconomy' since 2012 (minimum frequency of word repetition -3 times).

Fig. 4 shows a network of correlative links between these 37 keywords, consisting of 319 links and a total link strength of 564. The figure shows that the most frequently occurring keyword in publications is 'bioeconomy'. Of course, it could be considered the most relevant word because papers were selected using the keyword 'bioeconomy', which appears in 36 scientific publications and relates to 36 other keywords described as links. The second most relevant keyword is 'education' (32 links), in 16 scientific papers. The third most common word in 13 scientific papers is 'sustainable development' (23 links), 'sustainability' (14 links) in 11 scientific papers and 'human' (28 links), 'innovation' (22 links), 'Europe' (30 links) in 9 scientific papers. 'Bioeconomy' and 'education' are used the most and show up in most publications. Words 'human', 'innovation', and 'Europe' show up in fewer papers than words 'sustainable development' and 'sustainability', but they have more connections with other keywords in the network, which means that authors are using more common language and words in the papers to represent further scientific topic development and their importance in science.

Table 1 represents four clusters with distributed keywords in the bibliographic network, where word combinations 'education' AND 'bioeconomy' were used, selecting scientific papers in the Scopus database from 2012. The keyword appears once in one of the clusters. 
TABLE 1. REPRESENTED Clusters IN BIBLIOGRAPHIC NETWORK WITH THE WORD COMBINATION ‘EDUCATION’ AND ‘BIOECONOMY' SINCE 2012 (MINIMUM FREQUENCY OF WORD REPETITION - 3 TIMES)

\begin{tabular}{llll}
\hline Cluster 1 & Cluster 2 & Cluster 3 & Cluster 4 \\
\hline agriculture & article & bioeconomy & Europe \\
biomass & circular economy & environmental economics forest management \\
biotechnology & curricula & European union & forestry \\
climate change & education & green economy & stakeholder \\
decision making & industrial economics & higher education & student \\
economic aspect & oils and fats & innovation & students \\
economics & policy & intellectual capital & university sector \\
human & research & sustainability & \\
humans & technological development sustainable development & \\
International cooperation & & & \\
note & & & \\
priority journal & & & \\
\hline
\end{tabular}

It should be mentioned that VOSviewer is a quantitative analysis software, and qualitative analysis software should be used for further research. Notwithstanding the above, it is possible to understand the field of study in each cluster in which education with bioeconomy is related.

Cluster 1 represents keywords related to human involvement in agriculture and the development of bioeconomy using biotechnologies, where knowledge is essential. Education necessity for industrial economics is shown in Cluster 2, where technological development and research should be considered. Cluster 3 keywords are related to innovation necessity in bioeconomy, which should be done by higher education involvement for sustainable development. Cluster 4 represents the forestry sector and student education necessity for bioeconomy development.

Fig. 5 shows keywords' chronological appearance in the papers, where keywords in yellow, such as 'forest management', 'forestry', 'stakeholder', 'student', etc., appear more in up-todate publications, for example, in 2019. It could be explained that more significant research is applied to more carbon-neutral applications, for example, forest resources. Keywords in dark blue, such as 'technological development', 'policy', 'industrial economics', were performed already in 2016. Keywords in yellow show the latest development in research, which is considered in the forestry sector. More innovative applications in the forestry sector for bioeconomy development through education will be considered. 


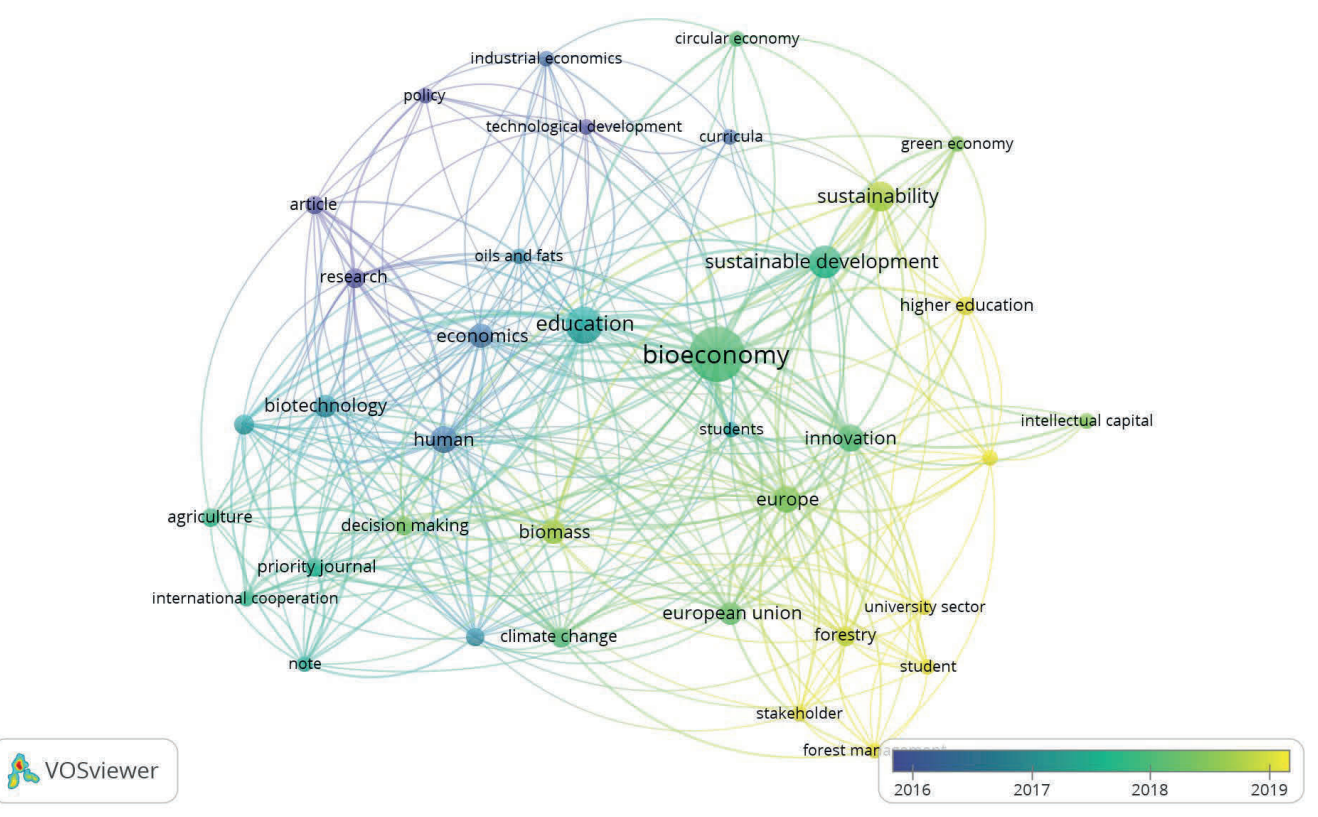

Fig. 5. Overlay (chronological) visualisation of the bibliography with the word combination 'education' and 'bioeconomy' since 2012 (minimum frequency of word repetition -3 times).

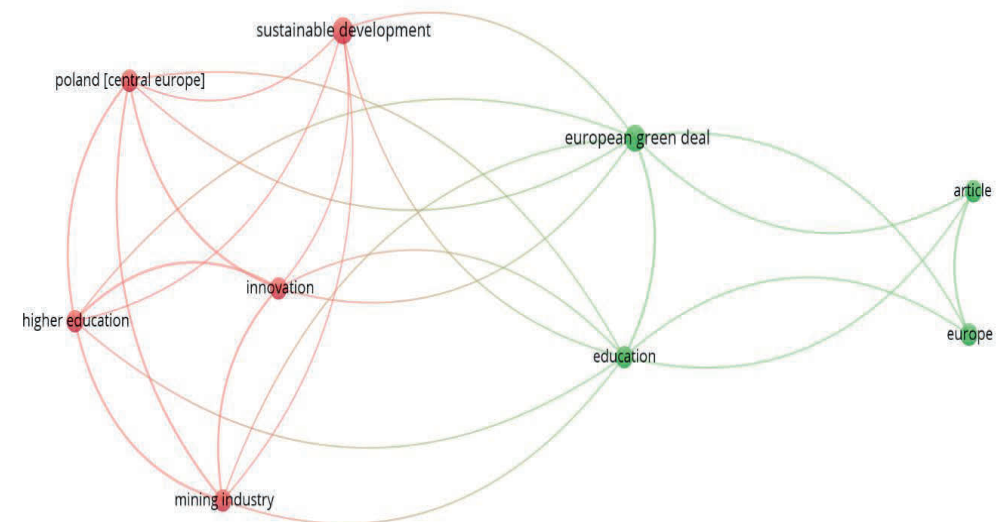

Fig. 6. Visualisation of the bibliography with the word combination 'education' and 'green deal' since 2019 (minimum frequency of word repetition -2 times).

Fig. 6 shows the connection of scientific articles with the word's 'education' and 'green deal'. Papers were selected from 2019, as the Green Deal document was published this year. In total, there are nine articles. It should be noted that the number of articles is much smaller compared to the above word combinations. 


\section{Conclusion}

Recently, the question of how the goals of the bioeconomy will be achieved is becoming more and more important, considering the framework of the Green Deal. One cornerstone is higher education in achieving these goals by implementing competence-based study programs, resulting in highly qualified bioeconomy specialists.

The study's primary goal was to identify the most used keywords deciphered in the studies so far, using the bibliographic software VOSviewer to identify research trends by selecting research papers in Scopus database, and choosing papers using words 'education', 'Green Deal', 'bioeconomy', in different combinations. Word combinations such as 'education AND bioeconomy AND skill', 'education AND bioeconomy and competence', 'education AND bioeconomy AND innovation', and 'education AND Green Deal AND innovation' were also compiled. Scientific publications with these word combinations alone were not selected and were therefore not used for further analysis. Instead, 'education AND bioeconomy', where minimum keyword occurrence is 3, and 'education AND Green Deal', where minimum keyword occurrence is 2, were used for further analysis. Scientific papers where the words 'bioeconomy' and 'Green Deal' were included were selected starting from 2012 and 2019, respectively. Thirty-seven corresponding keywords were obtained for visualisation, contained in four clusters: linking the bioeconomy and education in the agricultural sector (Cluster 1), connecting the bioeconomy and education in the industry (Cluster 2), linking the bioeconomy and education to innovation (Cluster 3) and linking the bioeconomy and education to forestry (Cluster 4). Also, 'forest management', 'forestry', 'stakeholder', 'student' are the most commonly used words in research in recent years. The research results have been obtained and help identify how research in higher education is currently underway through the bioeconomy and for developing new trends.

Further research should focus on how education explores these identified areas in clusters considering topics as bioeconomy, Green Deal, skills, education, competencies, and innovation as a whole.

\section{ACKNOWLEDGEMENT}

This research is funded by the Latvian Council of Science, project Bioeconomy in the shade of Green Deal (BioDeal), project No. lzp-2020/2-0321.

\section{REFERENCES}

[1] European Commission. A sustainable Bioeconomy for Europe: strengthening the connection between economy, society and the environment. Luxembourg: Publications Office of the European Union, 2018. https://doi.org/10.2777/478385

[2] Ministry of Agriculture Republic of Latvia. Latvijas Bioekonomikas stratēgija 2030 (Latvian Bioeconomy Strategy 2030.). Riga: ZM, 2017. (in Latvian)

[3] Pubule J., et al. Education for Advancing the Implementation of the Bioeconomy Goals: An Analysis of Master Study Programmes in Bioeconomy. Environmental and Climate Technologies 2020:24(2):149-159. https://doi.org/10.2478/rtuect-2020-0062

[4] European Green Deal | European Commission [Online]. [Accessed 21.12.2021]. Available: https://ec.europa.eu/info/strategy/priorities-2019-2024/european-green-deal_en

[5] Onpraphai T., et al. Sustaining biomaterials in bioeconomy: Roles of education and learning in mekong river basin. Forests 2021:12(12):1670. https://doi.org/10.3390/F12121670

[6] Pude R. Nachwachsende Rohstoffe aus der Region und für die Region (Renewable raw materials from the Region, and for the Region.). Berichte uber Landwirtschaft 2021:99(1). https://doi.org/10.12767/BUEL.V99I1.352 (in German)

[7] Pagliaro M. Preparing for the future: Solar energy and bioeconomy in the United Arab Emirates. Energy Science and Engineering 2019:7(5):1451-1457. https://doi.org/10.1002/ESE3.440 
[8] Nibbi L., Chiaramonti D., Palchetti E. Project BBChina: A new master program in three Chinese universities on biobased circular economy; from fields to bioenergy, biofuel and bioproducts. Energy Procedia 2019:158:1261-1266. https://doi.org/10.1016/J.EGYPRO.2019.01.416

[9] Grzyb K., Hartman B. D., Field K. G. Comparing industry and academia priorities in bioenergy education: a Delphi study. International Journal of Sustainable Energy 2018:37(10):956-969. https://doi.org/10.1080/14786451.2017.1402769

[10] Lask J., et al. The bioeconomist. Bioeconomy: Shaping the Transition to a Sustainable, Biobased Economy. Cham: Springer International Publishing, 2017:341-354. https://doi.org/10.1007/978-3-319-68152-8 12

[11] Muizniece I., et al. Circular Economy and Bioeconomy Interaction Development as Future for Rural Regions. Case Study of Aizkraukle Region in Latvia. Environmental and Climate Technologies 2019:23(3):129-146. https://doi.org/10.2478/RTUECT-2019-0084

[12] Pubule J., et al. Evaluation of the Environmental Engineering Study Programme at University. Environmental and Climate Technologies 2019:23(2):310-324. https://doi.org/10.2478/rtuect-2019-0070

[13] Urmetzer S., et al. Learning to change: Transformative knowledge for building a sustainable bioeconomy. Ecological Economics 2020:167:106435. https://doi.org/10.1016/J.ECOLECON.2019.106435

[14] Loeffler M., et al. Processing of Biobased Resources. In Lewandowski I. (eds) Bioeconomy: Shaping the Transition to a Sustainable, Biobased Economy. Cham: Springer, 2018:179-230. https://doi.org/10.1007/978-3-319-68152-8 7

[15] European Skills Agenda - Employment, Social Affairs \& Inclusion - European Commission [Online]. [Accessed 21.12.2021]. Available: https://ec.europa.eu/social/main.jsp?catId=1223\&langId=en

[16] van Eck N. J., Waltman L. Software survey: VOSviewer, a computer program for bibliometric mapping. Scientometrics 2010:84(2):523-538. https://doi.org/10.1007/s11192-009-0146-3

[17] Avelar A. B. A., da Silva-Oliveira K. D., da S. Pereira R. Education for advancing the implementation of the Sustainable Development Goals: A systematic approach. The International Journal of Management Education 2019:17(3):100322. https://doi.org/10.1016/J.IJME.2019.100322

[18] Abad-Segura E., et al. Effects of Circular Economy Policies on the Environment and Sustainable Growth: Worldwide Research. Sustainability 2020:12(14):5792. https://doi.org/10.3390/SU12145792 